\title{
Histological pattern and changes in extracellular matrix in aortic dissections
}

\author{
H SARIOLA, ${ }^{*}$ T VILJANEN, $\dagger$ R LUOSTO $\dagger$ \\ From the *Department of Pathology, University of Helsinki, and the $†$ Department of Thoracic and \\ Cardiovascular Surgery, University Central Hospital of Helsinki, Finland
}

SUMMARY Samples from 34 patients were studied both histologically and immunocytochemically by the indirect biotin-avidin peroxidase technique to analyse the distribution of the extracellular matrix components (type IV collagen, fibronectin, types I and III collagens) in dissection of the aorta. Most showed defects in type IV collagen around medial smooth muscle cells. Defects in smooth muscle cell basement membrane were found throughout the media in cystic medial degeneration and in medionecrosis, whereas in atherosclerosis such unlabelled areas were found only above advanced atherosclerotic plaques. In aortitis other defects in the smooth muscle cell basement membrane were found in areas of inflammatory infiltrates. In all of these conditions similar defects in fibronectin expression were also found. No defects in the expression of interstitial collagens type I and III were seen in the dissecting aortas. Moreover, cystic medial degeneration, medionecrosis, and atherosclerosis were characterised by intense staining of these interstitial matrix components. In the pathogenesis of the aortic dissection local changes in the basement membranes of the medial layer may be important.

Aortic dissection is the most common and often lethal catastrophy that occurs in the aorta. ${ }^{1}$ Controversy surrounds its pathogenesis. ${ }^{12}$ Recent studies emphasised the role of haemodynamic factors, especially hypertension, in its pathogenesis. ${ }^{2-6}$ Some connective tissue and metabolic diseases, however, increase the risk of aortic dissection at an early age. ${ }^{17-9}$ Therefore, the part played by defects in the aortic wall itself remains unclear.

Since the original description of idiopathic cystic medionecrosis by Erdheim ${ }^{7}$ medial changes have been regarded as having a central role in aortic dissection. ${ }^{16}$ At present, cystic medial degeneration is defined as the pooling of mucoid material and the appearance of cyst like structures in the media and medionecrosis as an apparent loss of nuclei in the media. ${ }^{2}$ Histological studies, however, have further indicated that none of the pathological features evident in dissecting aortas could be regarded as specific for this condition. ${ }^{2610-13}$

Although cystic medial degeneration (CMD) and medionecrosis commonly occur in dissecting aortas, these conditions are also often found in normal aortas. $^{26} \mathrm{~A}$ feature common to most dissecting aortas is the fragmentation of elastic fibres, ${ }^{13610}$ but this may

Accepted for publication 2 December 1985 be a rather non-specific reaction to various diseases that cause injury and repair in the aortic wall.

In recent years several studies have described the composition of the extracellular matrix (ECM) of the aortic wall. ${ }^{14-22}$ So far, however, no immunohistochemical studies have been presented on the distribution of such components in dissecting aorta. We therefore analysed the ECM composition of samples from dissecting aortas and compared it with those of the ECM found in the wall of normal aortas.

\section{Material and methods}

From 1964 to 198260 patients with aortic dissection underwent surgery at the department of thoracic and cardiovascular surgery, University Central Hospital of Helsinki. The dissections were divided according to DeBakey's criteria ${ }^{23}$ into three categories as follows: type I (20 patients); type II (15); type III (25). Twenty eight patients had hypertonia.

The files of the department of pathology, University of Helsinki, contained histological samples of the dissecting area from 34 patients. Of this group, 14 patients had hypertension before the onset of aortic dissection, while three patients presented with clinical signs of Marfan's syndrome. The samples had been routinely fixed in $4 \%$ buffered formalin and 
embedded in paraffin. For the histological analysis $5 \mu \mathrm{m}$ sections were cut and stained by van Gieson; haematoxylin and eosin; resorcin-fuchsin; alcian blue; and periodic acid Schiff. Additional $5 \mu \mathrm{m}$ sections were cut for immunocytochemical staining. Biopsy specimens of 12 ascending aortas removed during coronary bypass operations were used as control samples. No age matching was possible between the control and dissecting aorta groups. The samples of the control group were treated in the same way as those from patients with dissecting aortas.

\section{IMMUNOCYTOCHEMISTR Y}

Paraffin sections were deparaffinised in xylene, brought to phosphate buffered saline through decreasing concentrations of ethanol, then incubated in a $\mathbf{0 . 2 \%}$ pepsin solution for two hours. Recent studies have shown that ECM components can be reliably analysed in routinely processed formalin fixed samples after treatment with pepsin. ${ }^{6}$ For immunoperoxidase staining the biotin-avidin peroxidase kit (Vector Laboratories, Burlingame, California) was used. The sections treated with pepsin were incubated in $0.3 \% \mathrm{H}_{2} \mathrm{O}_{2}$ in methanol for 30 minutes, washed in phosphate buffered saline for 10 minutes; incubated for 30 minutes with the primary antiserum; washed in phosphate buffered saline for 10 minutes; incubated for 60 minutes with biotinylated second antibodies; washed in phosphate buffered saline for 10 minutes and then for 60 minutes in horseradish-peroxidaseavidin complex; washed in phosphate buffered saline for 10 minutes; reacted with 3,3'diaminobenzidine-tetrahydrochloride and $\mathrm{H}_{2} \mathrm{O}_{2}$ for five minutes; washed in tap water for five minutes, and mounted. No staining was seen when the primary antiserum was omitted or non-immune serum was used instead.

The affinity purified monospecific rabbit antibodies against types I, III, and IV collagens and fibronectin applied for this study have been described previously. ${ }^{25-28}$ They were kindly donated by Drs $R$ Timpl (Max Planck Institute, München, Federal Republic of Germany) and A Vaheri (University of Helsinki, Finland).

\section{Results}

\section{HISTOLOGY}

The histological survey of 34 dissecting aortas disclosed several distinct pathological entities: cystic medial degeneration (CMD), medionecrosis, atherosclerosis, and inflammation, but some aortas were normal. Atherosclerotic plaques were often present with medial changes. Hence classification into one histopathological entity was not possible in all cases. In addition, the degree of changes varied even within
Table 1 Histopathological features of samples from 34 patients with dissecting aorta operated on between 1964-82

\begin{tabular}{lr}
\hline Normal & 3 \\
Atherosclerosis & 16 \\
Cystic medial degeneration & 12 \\
Medionecrosis & 18 \\
Inflammation & 2 \\
Elastic fragmentation & 29 \\
Total scarring & 1 \\
\hline
\end{tabular}

samples from a single case. Table 1 shows the histopathological features of 34 dissecting aortas. Histologically, the control specimens were normal or had minor atherosclerotic changes. No medial changes were present.

Elastic fragmentation and a loss of elastic fibres in the media were seen in most patients. Only five had a normal elastic fibre pattern. Histologically, three of these aortas were normal and two had mild atherosclerosis. Fragmented elastic fibres were seen in association with all histopathological changes.

CMD was seen together with various degrees of medionecrosis (fig la), but medionecrosis was also seen without CMD above advanced atherosclerotic plaques. The three patients with Marfan's syndrome all showed typical CMD with increased staining of acid mucopolysaccharidic extracellular material and cyst like spaces in the media.

Various degrees of atherosclerosis were seen in the aortic samples of 16 patients. In samples with fatty streaks or fibrotic plaques the media was intact, and only mild, or no, elastic fragmentation was seen. In severely atherosclerotic samples (eight patients) the demarcation between the intima and media was not clear, and fibrosis also continued as far as the medial layer. In these areas fragmented elastic fibres could be seen and the number of nuclei was decreased. Some samples, however, had medial changes that seemed to be independent of the atherosclerosis, when CMD was seen in association with mild atherosclerotic changes.

Aortitis was seen in two cases. Pronounced inflammatory infiltrates were found in both, but in one they consisted almost exclusively of lymphocytes with a few histiocytes, and in the second mostly granulocytes with some eosinophilic leucocytes and lymphocytes (fig $1 \mathrm{~b}$ ). The histological picture in the first case is characteristic of a non-specific aortitis, but in the second case it was more acute. This patient developed the aortic dissection soon after giving birth.

Total scarring was found in one case: the aortic wall had been replaced by fibrous tissue and only remnants of medial cells or elastic fibres were found. In the remaining three cases the aortic wall was histologically normal. 


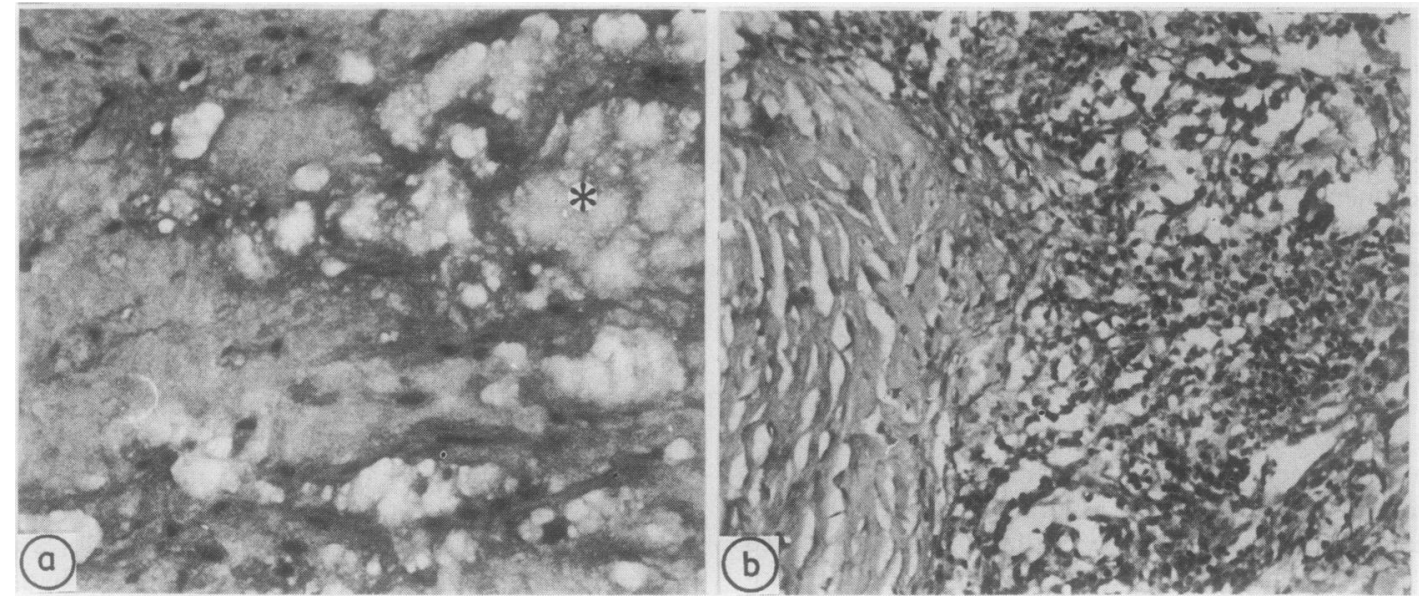

Fig 1 a) Micrograph of characteristic area of aortic media showing cystic medial degeneration with acid mucopolysaccharidic material containing cysts (asterix) and medionecrosis that can be seen as loss of nuclei and increase in amount of extracellular material.

b) In aortitis histological picture is characterised by infiltration of inflammatory cells (in this case mostly lymphocytes) in media. By using haematoxylin and eosin stain small neovascular capillaries in inflamed areas are difficult to recognise (compare with fig 2e). (Haematoxylin and eosin.) a) $\times 250 ; b) \times 150$.

\section{IMMUNOCYTOCHEMISTRY}

Type IV collagen was seen in control aortic specimens and histologically normal samples of the dissecting aortas in the subintimal basement membrane and in the media as longitudinal sheets between smooth muscle cells. The basement membrane of adventitial and vasa vasorum capillaries were brightly stained by these antibodies (fig 2a).

In aortas with CMD and medionecrosis the expression of the basement membrane collagen was often discontinuous and large unstained areas were often found (fig $2 b$ and $c$ ). In these areas elastic fibres were fragmented. A rough correlation could be seen between the quantity of fragmented elastic fibres and the defects of basement membrane collagen around smooth muscle cells in the media. In addition, unlabelled areas in the media were smaller, and the normal continuous expression of type IV collagen was better preserved in samples with mild and mod- erate medionecrosis than in those in which it was severe.

In specimens with mild or moderate atherosclerosis type IV collagen was seen in longitudinal sheets similar to those found in control aortas. In samples with advanced atherosclerotic lesions with medial scarring type IV collagen was also missing above the intimal plaque (fig 2d).

In the samples with aortitis numerous neovascular capillaries could be stained with antibodies against type IV collagen (fig 2e). In the areas with inflammatory cells the expression of type IV collagen was irregular and fragmented. In the samples with total scarring of the aortic wall no expression of type IV collagen was found around the medial cells but the subendothelial basement membrane was brightly stained (not shown).

Fibronectin was seen in the control samples throughout the wall: in the subendothelial basement

Table 2 Expression of extracellular matrix components in media of dissecting aortas as analysed by indirect biotin-avidin peroxidase technique*

\begin{tabular}{llll}
\hline Histology & Type IV collagen & Types I and III collagen & Fibronectin \\
\hline Atherosclerosis & D* & I & D \\
Cystic medial degeneration & D & Nor & D \\
Medionecrosis & D & N or I & D \\
Inflammation & D & I & D \\
Total scarring & - & D & \\
\hline
\end{tabular}

$\mathrm{N}=$ normal expression; $\mathrm{D}=$ defects in expression; $-=$ no expression; $\mathrm{I}=$ increased expression. * Above advanced atherosclerotic plaques; + in areas of inflammation; $\ddagger$ staining of the vasa is excluded. 

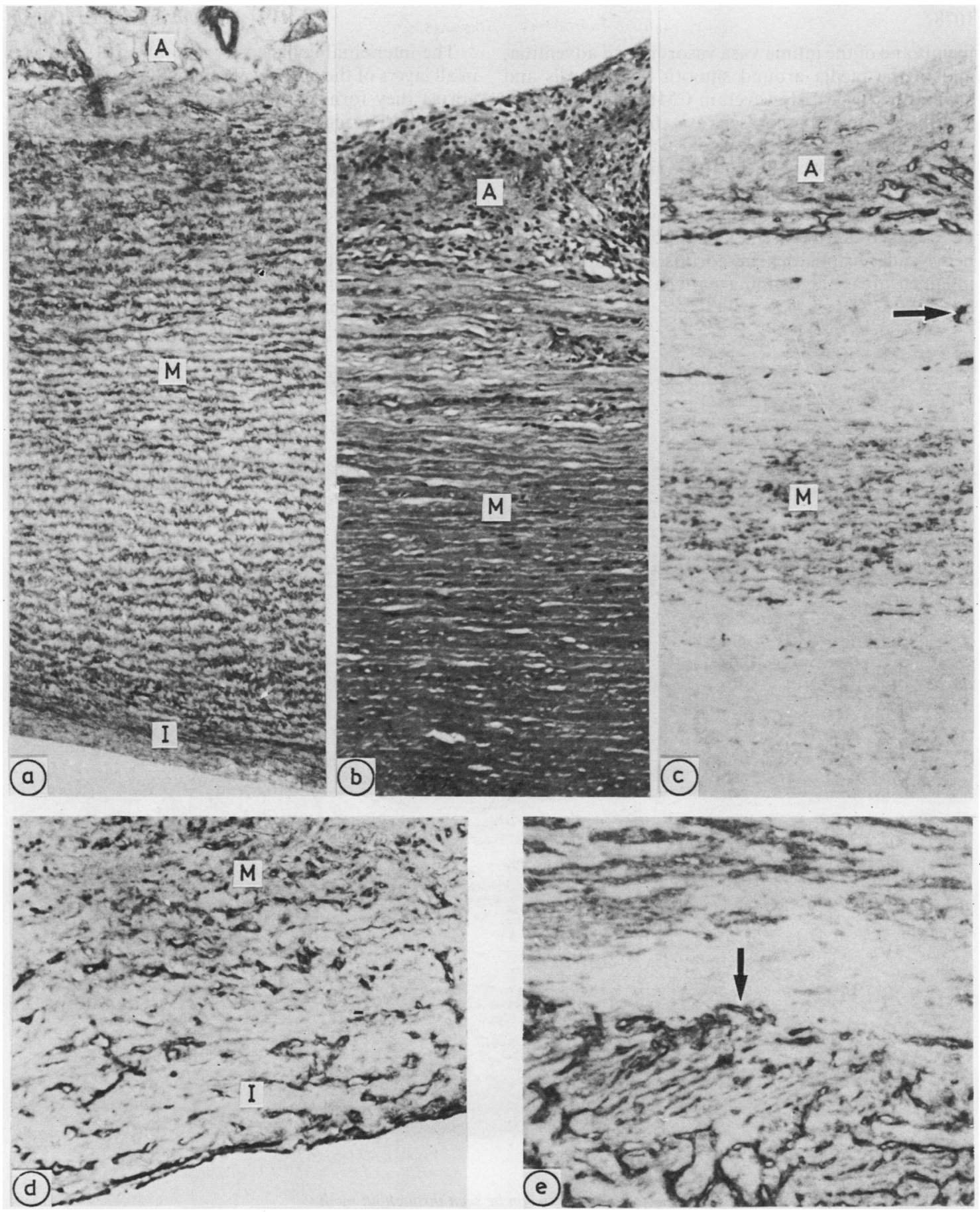

Fig 2 Expression of type IV collagen in different histopathological patterns of dissecting aortas.

a) In histologically normal aortas type IV collagen forms regular longitudinal sheets in media.

b) In severe cystic medial degeneration with medionecrosis only remnants of medial smooth muscle cells can be seen.

c) Adjacent section stained for type IV collagen shows large unstained areas around medial cells and labelled areas also have rather discontinuous and irregular staining pattern. Subendothelial basement membrane of vasa vasorum (arrow) is expressed normally.

d) Unlabelled areas in media can also be found in severe atherosclerosis but only above intimal plaque (I).

e) In aortitis numerous neovascular capillaries can be seen by the staining for type IV collagen (arrow).

$I=$ intima; $M=$ media; $\boldsymbol{A}=$ adventitia. ( (a) Indirect biotin-avidin peroxidase staining with antibodies against type IV collagen; (b) Haematoxylin and eosin.) $a-c \times 50, d-e \times 120$. 
membrane of the intima vasa vasorum and adventitia, and in the media around smooth muscle cells and adventitia (fig 3a). However, in CMD, medionecrosis (fig $3 \mathrm{~b}$ ) and severe atherosclerosis (fig $3 \mathrm{c}$ ) the expression of fibronectin in the media was distorted, and unstained areas were seen. In addition, fibronectin was not seen in such clear regular layers as in the control samples. As with the antibodies against type IV collagen antibodies against fibronectin stained neovascular capillaries in aortitis, but outside the inflamed areas the staining pattern was normal (fig 3d).
The interstitial collagens types I and III were seen in all layers of the aortic wall. In histologically normal aortas they formed thick longitudinal sheets in the media (fig 4a); in CMD, medionecrosis, and aortitis no defects of these fibres could be found (fig $4 b$ ). In atherosclerosis staining for interstitial collagens was intense in the intimal plaque, and in severe atherosclerosis the medial staining was also distorted (fig $4 c)$. In the case with total scarring of the aortic wall the media was stained throughout by the antibodies against types I and III collagens (not shown). Table 2 summarises the immunocytochemical findings.
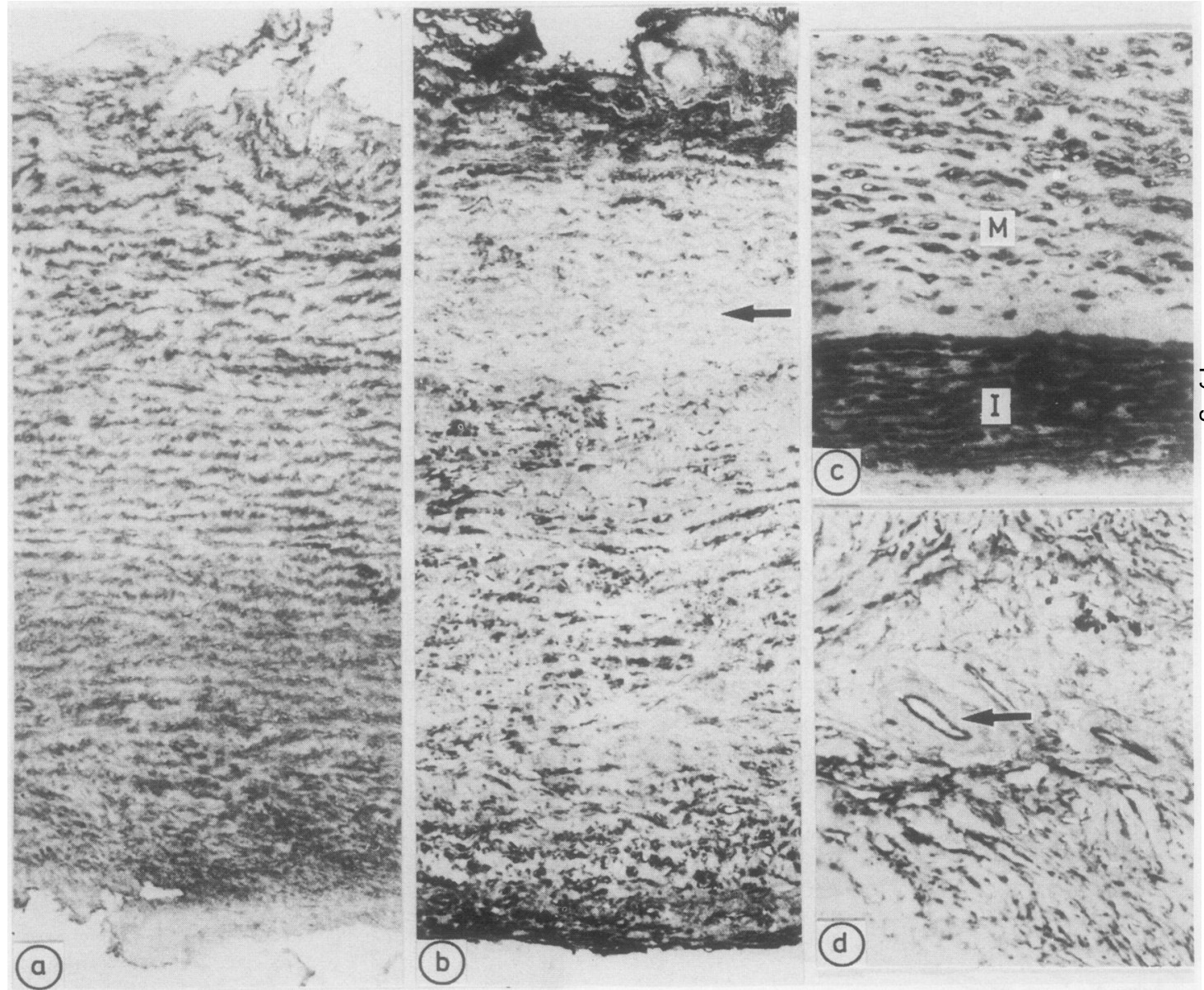

Fig 3 Expression of fibronectin in aortic dissection.

a) In histologically normal aortas staining for fibronectin can be seen throughout media.

b) Although in CMD and medionecrosis some unstained areas are found in media (arrow), distorted staining pattern is characteristic of fibronectin.

c) In mild atherosclerotic lesions intimal plaque (I) is intensely stained for fibronectin and medial (M) staining is normal. d) As with staining for type IV collagen, staining for fibronectin show numerous neovascular capillaries (arrow) and distorted staining pattern in aortitis.

$((a-d)$ indirect biotin-avidin peroxidase staining with antibodies against fibronectin) $a-b \times 50 ; c-d \times 120$. 

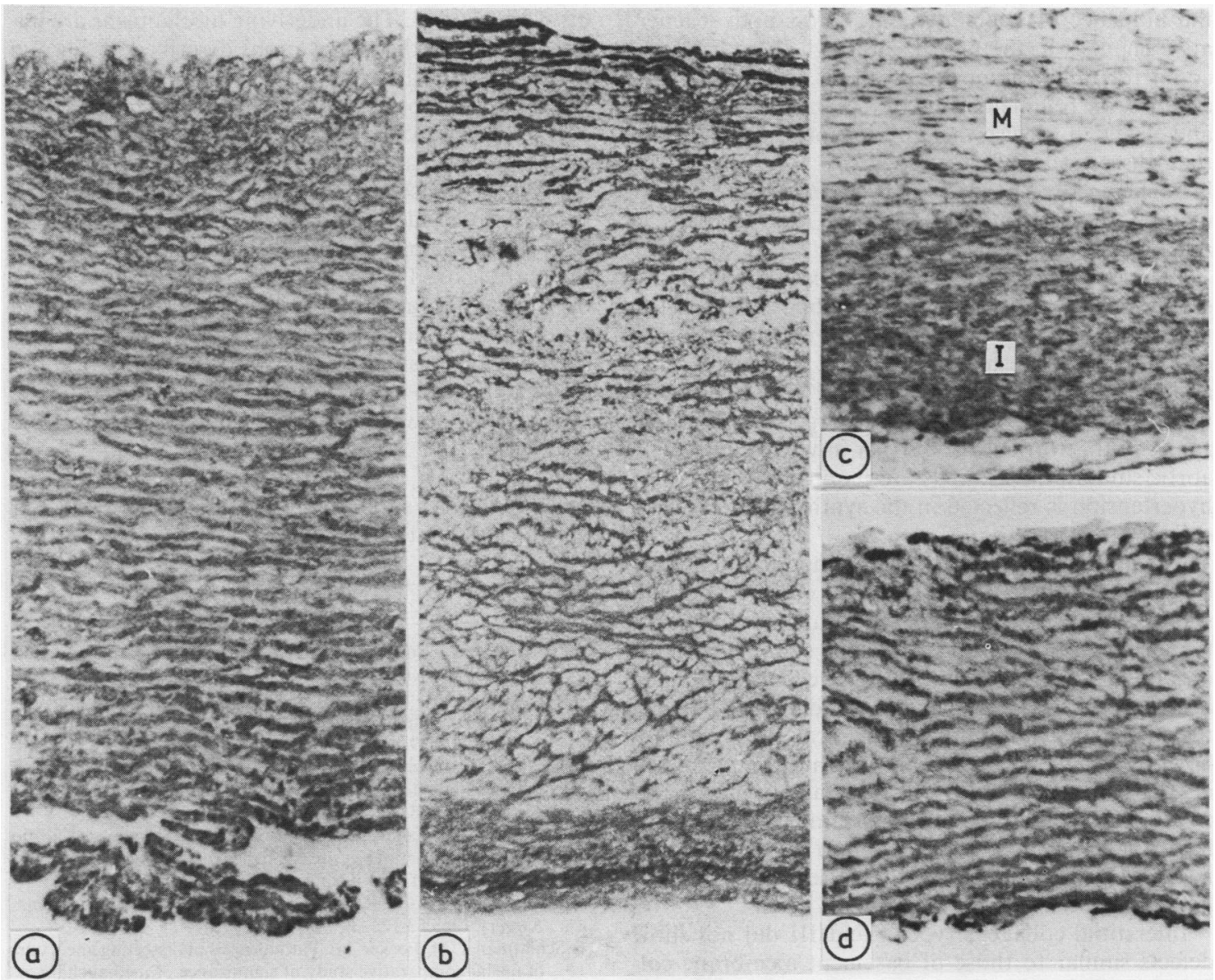

Fig 4 Expression of interstitial collagens types I and III in aortic dissection.

a) In histologically normal aortas interstitial collagens form bundles through media. Note that these layers are thicker than those formed by fibronectin and type IV collagen.

b) In CMD and medionecrosis bundles are not as regular as in normal aortas, but no defects can be found. In contrast, their expression is intense and relative proportion of interstitial collagens seems to be increased.

c) In atherosclerosis a similar intense staining can be seen in intimal plaque (I) and media (M).

d) In aortitis interstitial collagens are expressed normally in media.

(Indirect biotin-avidin peroxidase stainings with antibodies $(a, b, d)$ against type III collagen; and (c) against type I collagen.) $a-d \times 50$.

\section{Discussion}

Our histological and immunohistochemical survey of dissecting aortas shows that, in association with various histopathologic changes in the media, defects can be found in the expression of fibronectin and the basement membrane specific type IV collagen around medial smooth muscle cells. For the interstitial ECM components types I and III collagens the expression was normal or even pronounced compared with that of normal aortas.
The results presented here suggest that CMD and medionecrosis lead not only to a fragmentation of elastic fibres but also to a loss of basement membrane components around medial smooth muscle cells. This may not, however, represent a systemic incompetence of cells to produce basement membrane matrix, as defects were local in the aortic media, and the subendothelial basement membrane of the intima and vasa vasorum were expressed normally. Nonetheless, because some connective tissue diseases increase the risk of aortic dissection, an abnormal extracellular 
matrix assembly could predispose the aortic wall to the influence of haemodynamic stress and degenerative changes in the media, although these cases account for only a minority of all dissections. A local absence or fragmentation of basement membranes and elastic fibres elsewhere in the aorta could explain the dissection of histologically and immunohistochemically "normal" aortas. Small local defects of type IV collagen were especially characteristic in aortitis and atherosclerosis.

Increased levels of elastases have been shown in dissecting aortas. ${ }^{7} \mathrm{~A}$ recent study proposed that elastases can also remove basement membrane collagen. ${ }^{32}$ Our results suggest that the elastic fibres and the medial smooth muscle cell basement membrane collagen may be the main targets for these enzymes in the aortic wall. Further in vitro studies with aortic smooth muscle cells are required to show how hypertension is reflected in the synthesis of elastases, collagenases, and the ECM.

The immunohistochemical findings in this study clearly correlated with histological changes, and, to some extent, with the degree of fragmentation of elastic fibres. Thus we propose that the staining patterns of type IV collagen and fibronectin correspond to an absence of these components in the damaged areas of the media. An immunohistochemical study cannot, however, exclude the possibility of antigenetic masking. Recent observations show that an enzymatic pretreatment of paraffin embedded samples with pepsin has, in other instances, turned out to be a reliable tool in the immunohistochemical analyses of ECM components. ${ }^{2433}$

Interstitial collagens types I and III did not show defects similar to those of basement membrane collagen and fibronectin. Indeed, they were found in abundancy, although sometimes in a distorted pattern. Their relative proportion in the aortic media seemed to be increased. This phenomenon could reflect a slow reparative process, compensating for degenerative events in the media. Hence in connective tissue disorders and metabolic diseases an abnormal ECM may lead to an increased compliance of the aortic wall. ${ }^{13} 29-31$ The high compliance could lead to the degeneration of medial smooth muscle cells, and, finally, to the degradation of their basement membrane, as well as to a loss of elastic fibres. Cells participating in the regeneration may slowly replace the smooth muscle cells so that the ECM becomes the interstitial type. The same sequence may occur in patients with no metabolic disorders, when the sequence leading to the change in the ECM is initiated by haemodynamic conditions, such as hypertonia or abnormal blood flow, as in aortic valve diseases.

In conclusion, using a sensitive immunocytochemical method, we showed that defects can be found in the basement membranes of the media in dissecting aortas. The underlying mechanisms are unclear. Based on the observations described in this and other recent papers, however, ${ }^{1620}$ the following scheme can be presented for the pathogenesis of the aortic dissection: various different diseases may lead to degeneration and necrosis of smooth muscle cells, a loss of their basement membrane, and an increased production of interstitial type matrix, most probably, by cells participating in the regeneration-namely, the fibroblasts. This sequence may be initiated either by hypertonia, abnormal blood flow, or connective tissue diseases that increase the aortic compliance or haemodynamic stress against the wall. Very local defects can be seen in aortitis and atherosclerosis. These "weak", loci, however, could be enough to initiate the dissection.

This study was supported by a grant from the Ida Montin Foundation.

\section{References}

1 Roberts WC. Aortic dissection: anatomy, consequences and causes. Aim Heart J 1981;101:195-214.

2 Schlatman TJM, Becker AE. Histologic changes in the normal aging aorta: implications for dissecting aortic aneurysm. Am J Cardiol 1977;39:13-20.

3 Carlson RG, Lillehei CW, Edwards JE. Cystic median necrosis of the ascending aorta in relation to age and hypertension. Am J Cardiol 1970;25:411-20.

4 McKusick VA, Logue RB, Bahnson HT. Association of aortic valvular disease and cystic median necrosis of the ascendent aorta: report of four instances. Circulation 1957;16:188-95.

5 Hume DM, Porter RR. Acute dissecting aortic aneurysms. Surgery 1963;53:122-32.

6 Schlatman TJM, Becker AE. Pathogenesis of dissecting aneurysm of aorta: comparative study of significance of medial changes. Am J Cardiol 1977;39:21-6.

7 Deroutee S, Hornebeck W, Loisancea D, Godeau G, Cachera JP, Robert L. Studies on elastic tissue of aorta in aortic dissection and Marfan syndrome. Pathol Biol 1981;29:539-49.

8 McKusick VA. Heritable disorders of connective tissue. St Louis: Mosby, 1956.

9 Pope FM, Martin GR, Lichtenstein JR, et al. Patients with EhlerDanlos syndrome type IV lack type III collagen. Proc Natl Acad Sci USA 1975;72:1314-5.

10 Erdheim J. Medionecrosis aortae idiopathica. Virchows Arch (Pathol Anat) 1929;273:454-79.

11 Klima T, Spjut HJ, Coelho A, et al. The morphology of ascending aortic aneurysms. Hum Pathol 1982;14:810-8.

12 Hirst AE, Johns VJ, Kline SW. Dissecting aneurysm of the aorta: a review of 50 cases. Medicine 1968;37:217-30.

13 Bolis GB, Ferranti MG. L'aneurysma dissecante dell'aorta: analisi di 35 casi autoptici perugia 1960-81. Pathologica 1982;74:65-73.

14 Trelstad RL. Human aorta collagens: evidence for three distinct species. Biochem Biophys Res Comm 1974;57:717-25.

15 Mayne R, Vail M, Miller E. Characterization of the collagen chains synthetized by cultured smooth muscle cells derived from Rhesus monkey thoracic aorta. Biochemistry 1978;17:446-52.

16 Mayne R, Zettergren JG. Type IV collagen from chicken muscular tissues. Isolation and characterization of the pepsin 
resistant fragments. Biochem 1978:19:4065-72.

17 Stenman S, Vaheri A. Distribution of major connective tissue protein, fibronectin, in normal human tissues. $J$ Exp Med 1978;147:1054-64.

18 Wick G, Glanville RW, Timpl R. Characterization of antibodies to basement membrane (type IV) collagen in immunohistological studies. Immunobiol 1979;156:372-81.

19 Fitch JM, Gibney E, Sanderson RD, Mayne R, Linsenmayer TF. Domain and basement membrane specificity of a monoclonal antibody against chicken type IV collagen. J Cell Biol 1982;95:641-7.

20 Inberg M, Penttinen R. Desmosin in aneurysms of the ascending aorta (annuloaortic ectasia). Biochem Biophys Acta 1982;717:105-13.

21 Jensen BA, Hölund B, Clemmensen I. Demonstration of fibronectin in normal and injured aorta by an indirect immunoperoxidase technique. Histochemistry 1983;77:395-408.

22 Hendrix MJC. Localization of collagen types in the embryonic heart and aorta using immunohistochemistry. In: Thomas Pexieder, ed. Perspectives in cardiovascular research. Vol 5. Mechanisms. New York: Raven Press, 1981:213-25.

23 DeBakey ME, Henley WS, Cooley DA, Morris GC, Crewford ES, Beall AC. Surgical management of dissecting aneurysms of the aorta. J Thorac Cardiovasc Surg 1965;49:130-41.

24 Ekblom P, Miettinen M, Rapola J, Foidart JM. Demonstration of laminin, a basement membrane glycoprotein, in routinely processed formalin-fixed human tissues. Histochemistry 1982;675:301-7.

25 Timpl R, Wick G, Gay S. Antibodies to distinct types of collagen and procollagen and their application to immunohistology. $J$
Immunol Methods 1977;18:165-82.

26 Timpl R, Glanville RW, Wick G, Martin GR. Immunochemical study of basement membrane (type IV) collagens. Immunology 1979;38:109-16.

27 Timpl R, Martin GR. Components of basement membranes. In: Furthmayr H, Immunochemistry of the extracellular matrix. Florida: CRC Press, 1982;119-50.

28 Vaheri A, Mosher DF. High molecular weight, cell-surface associated glycoprotein (fibronectin) lost in malignant transformation. Biochem Biophys Acta 1978;516:1-25.

29 Child AH, Dorrance DE, Jay B, Pope FM, Jones RB, Gosling RG, Aortic compliance in connective tissue disorders affecting the eye. Ophthalmic Paediatrics and Genetics 1981;1:59-76.

30 Pope FM, Nicholls AC, Narcisi P, Bartlett J, Neril-Dweyer G, Doshi B. Some patients with cerebral aneurysms are deficient in type III collagen. Lancet 1981;i:973.

31 Resek G, Olivieri S. Aortic compliance in patients with ruptured intracranial aneurysms. Lancet 1983;i:939.

32 Levinson G, Bradley TJ. Removal of insect basal laminae using elastase. Tissue Cell 1984;16:367.

33 Sariola H, Ekblom P, Rapola J, Vaheri A, Timpl R. Extracellular matrix and epithelial differentiation of Wilms tumor. Am $J$ Pathol 1985;118:96-107.

Requests for reprints to: Dr Hannu Sariola, Department of Pathology, University of Helsinki, Haartmanninkatu 3, 00290 Helsinki, Finland. 